\title{
Who, What, Where, When, and How? A Typology of Drought Decision-Making on Public and Tribal Lands in the North-Central United States 0
}

\author{
Tyler A. BeEton And Shannon M. MCNeEley \\ Natural Resource Ecology Laboratory, Colorado State University, Fort Collins, Colorado
}

(Manuscript received 7 November 2019, in final form 17 April 2020)

\begin{abstract}
Although drought is a natural part of climate across the north-central United States, how drought is experienced and responded to is the result of complex biophysical and social processes. Climate change assessments indicate drought impacts will likely worsen in the future, which will further challenge decisionmaking. Here, a drought management decision typology is empirically developed from synthesis of three indepth case studies using a modified grounded-theory approach. The typology highlights 1) the entity or entities involved, 2) management sectors, 3) decision types, 4) spatial and temporal scale(s) of decisionmaking, and 5) barriers that inhibit decision-making. Findings indicate similarities in decision types and barriers across cases. Changes in operations, practices, or behaviors; information and technology; and legal or policy changes were the most common decision types, while commonly cited barriers were institutional constraints, fragmented decision-making, and limited personnel and financial resources. Yet barriers and responses also differed within and between sectors and jurisdictions. Several barriers inhibited anticipatory, regional, and interagency drought response, such as limited institutional support, competing mandates, limited resources, lack of usable information, limits to interagency fund transfers, and historical context and distrust among entities. Findings underscore the importance of documenting nuanced decision-making in local places and broader generalizations in decision-making across scales. This contributes to the goal of developing drought science that is actionable for decision-making.
\end{abstract}

\section{Introduction}

Drought is a natural part of climate variability across the north-central United States. Public and tribal land and resource managers and users are accustomed to responding to, recovering from, and preparing for, drought. Yet how drought is experienced and subsequently managed is the result of complex and interacting biophysical and social factors (Glantz 1994; Van Loon et al. 2016; Kallis 2008). Biophysical factors, including the effectiveness, timing, and form of precipitation, combined with differences in drought onset, severity, and duration all affect the extent to which sectors and livelihoods are impacted and management responses (Kallis 2008; Van Loon et al. 2016; McNeeley et al. 2016; Wilhite et al. 2014). Climate change assessments

\footnotetext{
Supplemental information related to this paper is available at the Journals Online website: https://doi.org/10.1175/WCAS-D-190137.s1.

Corresponding author: Tyler A. Beeton, tyler.beeton@colostate.edu
}

indicate that future droughts will likely become more frequent, intense, and sustained (Conant et al. 2018; Gonzalez et al. 2018; Cook et al. 2015), which will further challenge drought management.

Several recent case studies have documented the sociocultural, institutional, political, and economic factors that cause differential vulnerabilities and capacities to respond to drought (e.g., Dilling et al. 2019; Jedd et al. 2018; Wilmer and Fernández-Giménez 2015; Kachergis et al. 2014; Haigh et al. 2019; Chief et al. 2016; Hill and Engle 2013; McNeeley et al. 2016; Beeton et al. 2019; McNeeley et al. 2018; AghaKouchak et al. 2015). For example, increased management flexibility in season would allow permittees on public lands to respond to drought-related changes (e.g., later timing of forage production, water availability) (Beeton and McNeeley 2020; McNeeley et al. 2017b). However, incorporating adaptive management is challenging for several reasons, one of which is that public lands managers must evaluate the myriad and potentially uncertain actions and their environmental impacts as per the National Environmental Policy Act (NEPA) (Nave et al. 2020; McNeeley et al. 2017b). 
Relatedly, managing agencies' monitoring resources required to adaptively manage resources during drought are often lacking (Nave et al. 2020; McNeeley et al. 2017b). Also, complex water rights can cause disincentives to conserve water across different users during drought, narrow water use to one sector and/or prioritize sectors, or provide water administrative authority to actors that are disconnected from local resource management issues (Hill and Engle 2013; McNeeley 2017; McNeeley et al. 2016). Inadequate physical water infrastructure can inhibit the ability to store water for late-season use, efficiently allocate water, and/or monitor water availability during drought and nondrought years (Chief et al. 2016; McNeeley et al. 2018). Additionally, individual users or entities make decisions based on their respective risk perceptions, drought experiences, available resources, and market conditions (Wilmer and FernándezGiménez 2015; Haigh et al. 2019; Kachergis et al. 2014; Renn 2011). These case studies are critical to document differential drought responses and the determinants of drought vulnerability that are unique to social-ecological systems (Ford et al. 2010; O'Brien et al. 2007; Smit and Pilifosova 2003; Kallis 2008; Wandel et al. 2016; Smit and Wandel 2006). Yet few empirical studies document the portfolio of drought decision-making across management contexts, jurisdictions, and scales in public and tribal lands contexts in the north-central United States.

To address this research gap, we present a drought decision typology - that is, the classification of distinct, empirically derived decisions into types or categories. We developed this from the synthesis of three in-depth case studies on public and tribal lands. The typology documents 1) decision types or categories; 2) decisionmaker(s); 3) management sectors; 4) spatial, temporal, and administrative scales of decision-making; and 5) barriers that inhibit drought response and preparedness. We compare and contrast across jurisdictions, cases, and management sectors. Our objective is to demonstrate the importance of understanding the complexities and nuances in local-level decision-making while also identifying broader generalizations and gaps in drought decision-making across contexts and scales.

\section{Existing typologies of climate change and drought adaptation and barriers to adaptation}

Existing typologies of climate change and drought adaptation are reviewed below (see Table S1 in the online supplemental material for a comprehensive list of adaptation activities and citations). While the majority of typologies were developed in the context of climate change adaptation rather than drought adaptation, they offer a useful framework to situate our work. Typologies have been used to characterize response types (i.e., forms), spatial and temporal scales of actions, entities involved, administrative scales of decision-making, sectors addressed, and the barriers that inhibit action. In the climate adaptation literature, Smit et al. (2000) and subsequent work (e.g., Smit and Pilifosova 2003; Smit and Skinner 2002) compiled the first comprehensive review of adaptation types. They identified 12 distinct forms of adaptation, including administrative, technological, behavioral, financial, institutional, legal, managerial, organizational, political, practical, structural, and technological. Subsequently, Biagini et al. (2014) synthesized theoretical and empirical typologies of adaptation actions, which were then compared to a typology they developed from analysis of 133 adaptation projects financed by the United Nations Framework Convention on Climate Change. They identified 10 categories of adaptation actions, which included capacity building, management and planning, practice or behavior, information, physical infrastructure, warning/observing systems, green infrastructure, financing, and technology. Many of these categories aligned with previous typologies. Travis (2010) reviewed the natural hazards and disasters literature and identified six response types that reduce exposure to extremes and vulnerability. These included technological control and intervention; physical protection and barriers; monitoring, forecasting, and early warning systems; building codes and engineering design standards; relief and insurance mechanisms; and land-use changes. Wilhite et al. (2000) and others at the National Drought Mitigation Center applied the cycle of disaster management to drought management, distinguishing between crisis and risk management actions. Crisis management, or recovery actions, are typified by reactive responses during or following drought and include assessment of the impact, responses following drought, recovery, and reconstruction. In contrast, risk management actions, also called protection actions, include proactive responses to prepare for drought, such as short- and long-term mitigation actions, planning, and development of prediction and early warning systems. Although both types of drought management actions are important and needed, studies have shown that actions are often disproportionately reactive, crisis management responses aimed at reducing drought impacts rather than proactive, risk management actions that address the causes of vulnerability and promote drought resilience (e.g., Wilhite et al. 2014; Fu et al. 2013; Jedd 2019). Relatedly, the drought risk analysis framework emphasizes preemptive development of hazard and vulnerability assessments to assess drought risk, which could then be used to inform mitigation actions for planning efforts (Fu et al. 2013; Hayes et al. 2004). 
While some assessments addressed adaptation actions across several sectors (e.g., Ford et al. 2015; Lesnikowski et al. 2016; Robinson 2017), others assessed actions among specific sectors, for example, agriculture or water (e.g., Engle 2012; Smit and Skinner 2002; Wilmer and Fernández-Giménez 2015). With regard to temporal scale, scholars have differentiated between the timing of action relative to a stimulus, such as drought, and the duration of response. The timing of action relevant to the stimulus has been described as proactive, concurrent, or reactive, while the duration of response has been characterized as tactical, strategic, or structural (e.g., Meempatta et al. 2019; Risbey et al. 1999; Smit et al. 2000). In the drought management literature, reactive and proactive actions have been used interchangeably with crisis and risk management actions, respectively (e.g., Cai et al. 2015; Wilhite 2017, 2000; Wilhite et al. 2000).

Typologies that characterize climate-related actions at the geographic and administrative scale at which they occurred generally ranged from hyperlocal (e.g., plot, field, and farm) to national-level actions to more general characterizations, such as distinguishing between local, regional, and national actions (e.g., Fidelman et al. 2013; Smit and Skinner 2002). Additionally, Fidelman et al. (2013) differentiated actions taken within and across administrative scales, that is, horizontal and vertical actions. Differences in actions were also highlighted across entities, such as between farmers, local governments, and federal agencies (Smit and Skinner 2002; Lesnikowski et al. 2013).

Last, several studies have identified the types of barriers that inhibit response to climate variability and change on public and nonpublic lands (e.g., Adger et al. 2007; Bierbaum et al. 2013; Biesbroek et al. 2013; Eisenack et al. 2014; Moser and Ekstrom 2010; Archie et al. 2012; Jantarasami et al. 2010; Kemp et al. 2015; Timberlake and Schultz 2017). As part of the third National Climate Assessment, Bierbaum et al. (2013) synthesized the climate change adaptation literature and identified six categories of barriers to climate change adaptation, including climate change information and decision-making; lack of resources to begin and sustain adaptation efforts; fragmentation of decision-making; institutional constraints; lack of leadership; and divergent risk perceptions, cultures, and values. These typologies helped frame the drought decision typology presented below.

\section{Methods}

\section{a. Comparative case study approach: Drought risk and adaptation in the interior}

This research is a synthesis effort from the Drought Risk and Adaptation in the Interior (DRAI) project, which is funded by the North Central Climate Adaptation Science Center. DRAI researchers conducted placebased, in-depth social-ecological system vulnerability assessments to document drought impacts, risks, responses, and barriers among Department of the Interior (DOI), tribal, and other land and resource managers. We employed a determinants and analog approach to vulnerability assessment (Ford et al. 2010; Smit and Pilifosova 2003; McNeeley and Shulski 2011; Smit and Wandel 2006; Füssel and Klein 2006; Beeton et al. 2019). A determinants approach depends on close consultation with resource managers to identify the underlying drivers of vulnerability. An analog approach identifies past drought events as a focal point to further explore how droughts were experienced, who or what was impacted, what was done in response or to prepare for drought, and what factors constrained drought response. These provide a starting point to gauge plausible and desirable response options in the future, and highlight gaps, or needs, to better prepare for drought. Comparative case studies are particularly useful approaches to identify location- and context-specific response capacities and barriers and uncover more generalized conclusions across scales (Ford et al. 2010; McNeeley et al. 2017a).

\section{b. Case studies}

We conducted research in three high drought risk and multijurisdictional landscapes across the north-central United States. These case studies included the Yampa River basin (YRB) in northwest Colorado, southwest South Dakota (SWSD), and Wind River Reservation (WRR) in west-central Wyoming (Fig. 1). The region has experienced several extreme to exceptional droughts since 2000 (Fig. 2). Here, the DOI manages multiple resources and livelihoods (Mount et al. 2016). For example, the Bureau of Land Management (BLM) manages range and special recreation permittees, the National Park Service (NPS) and U.S. Fish and Wildlife Service (FWS) protect native and threatened or endangered fish and wildlife populations, and the Bureau of Indian Affairs (BIA) manages grazing permits and irrigation projects on tribal lands. Lands in the YRB are managed by the BLM, NPS, FWS, and U.S. Forest Service (USFS), and these entities interact with various state and district water managers. Extreme drought can limit the amount of physically and legally available water for agricultural, municipal, and energy sectors, and water available for four endangered fish species protected under the interagency Upper Colorado River Endangered Fish Recovery Program (McNeeley 2014). SWSD contains lands managed by the NPS, BLM, USFS National Grasslands, and two Indian reservations (a federal designation) and is home to the headquarters of the 


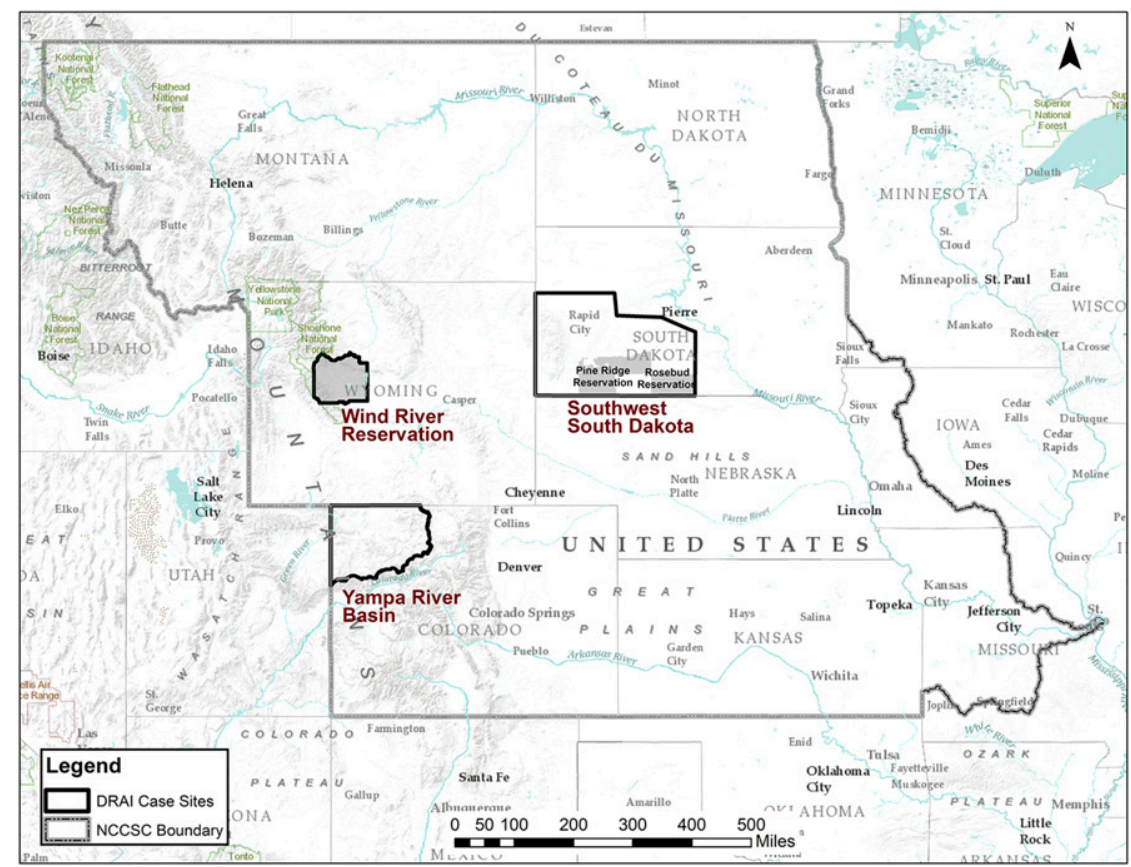

FIG. 1. Case studies (black polygons) that were included in the DRAI project and included in this assessment. The surrounding area (large gray polygon) denotes the regional boundaries of the North Central Science Center (NCCSC, now the North Central Climate Adaptation Science Center), which encompasses the states of Montana, Wyoming, Colorado, Kansas, Nebraska, South Dakota, North Dakota, and part of Missouri. This roughly follows the Missouri River basin. Gray-shaded areas represent Indian reservations in the case studies.

InterTribal Buffalo Council (ITBC). Bison and cattle ranching are common livelihood strategies, and both the NPS and tribes manage bison herds. Drought affects the timing and amount of forage and water production needed to support ranching livelihoods and bison conservation efforts (Beeton et al. 2019). In the WRR, water resources are managed by multiple agencies including the Office of the Tribal Water Engineer (TWE) and the Wind River Water Resources Control Board (WRCB), the BIA, which manages reservoir withdrawals and irrigation infrastructure in the Wind River Federal Irrigation Project, and the Wyoming State Engineer's Office, which has authority over water administration on the reservation. The FWS supports tribes in managing fish and wildlife of tribal and federal concern. Drought causes deleterious impacts to the reservation's agricultural production as well as fish and wildlife important to their subsistence and cultural activities (McNeeley et al. 2018).

These case studies provide excellent examples to compare the types of drought management decisions that have occurred and the barriers that inhibited drought response within and across management sectors, jurisdictions, and scales.

\section{c. Data collection and analysis}

We conducted 41 in-depth, semistructured interviews with natural resource managers from the DOI $(n=16)$

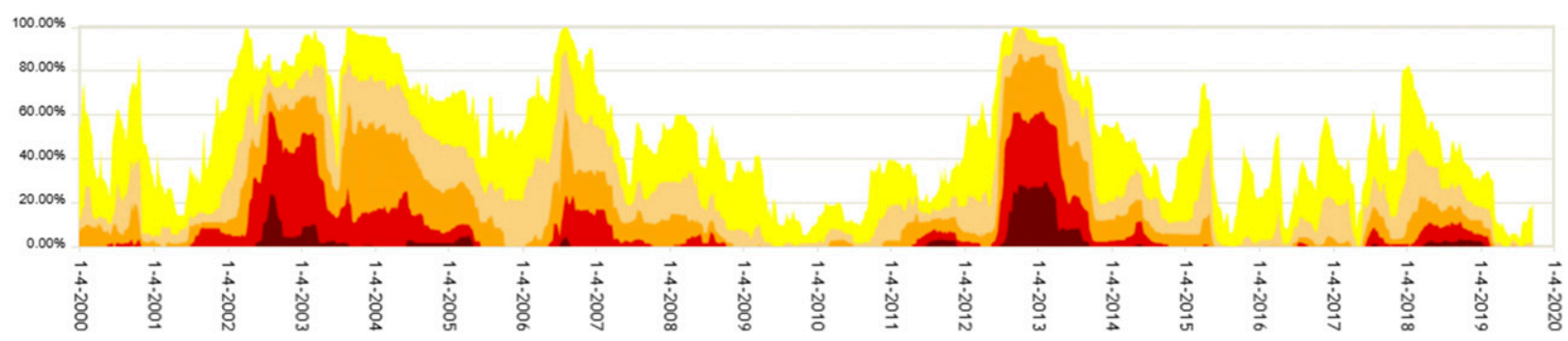

FIG. 2. Percent area of the "High Plains" in drought, according to the U.S. Drought Monitor, over 2000-19. Yellow = D0, abnormally dry; $\tan =\mathrm{D} 1$, moderate drought; orange $=\mathrm{D} 2$, severe drought; red = D3, extreme drought; and dark red = D4, exceptional drought. Source: National Drought Mitigation Center. 
and tribes and tribal organizations $(n=20)$. We also interviewed non-DOI managers, including state water managers $(n=4)$ and a Natural Resource Conservation Service manager $(n=1)$ who had direct roles in DOI and/or tribal management concerns and worked with these entities. Interviews were carried out in three case sites, including the YRB $(n=7)$, SWSD $(n=12)$, and WRR $(n=22)$. We used a purposive sampling strategy, which is a common approach to recruit participants when the questions require extensive local knowledge and experience pertaining to the research questions (Bernard 2011; Patton 2002). Participants were identified through agency contacts from previous work, agency websites, and correspondence with agency supervisors to identify appropriate managers to interview. The same interview protocol was administered in each case study to allow for cross-case comparative analysis. Interview topics pertinent to this analysis were 1) drought management decisions, 2) cross-agency collaboration and conflict during drought, 3) adaptative capacities to respond to and prepare for drought, and 4) barriers that inhibit drought response (see appendix for interview protocol).

Interviews were audio recorded, transcribed, and analyzed in Atlas.ti following a modified grounded-theory approach. Grounded theory is a set of prescriptive guidelines for iteratively and inductively analyzing qualitative data (Bryant and Charmaz 2007; Glaser and Strauss 1967). The approach requires inductive coding of text segments, constant comparison of segments and codes within and across cases, and memo writing to link codes to higher-order concepts (Bryant and Charmaz 2007; Corbin and Strauss 2008). A modified groundedtheory approach uses the same set of prescriptive guidelines but acknowledges that researchers' professional experience and theoretical perspectives affects how data are collected, analyzed, and interpreted (Charmaz 2011, 2006). This "constructivist" method allows for researchers and participants to coproduce knowledge where concepts can inductively "emerge" as in the traditional sense of a grounded-theory approach, but they can also be situated within the context of relevant theoretical and empirical literature (Mills et al. 2006; Thornberg 2012).

To develop the typology, we first constructed an operational definition of a drought decision. We defined a drought decision as a decision made in response to, or in preparation for, drought in order to reduce impacts to, and vulnerability of, people, sectors, species, and/or ecosystems to drought. We then analyzed the interviews and flagged segments of text that described a drought decision, or decisions, and segments that described barriers to drought response and preparedness. For each flagged text segment, we developed codes inductively from the interviews. Inductive codes were then analyzed and situated within relevant concepts from the drought and climate change adaptation literature (section 2) to frame the typology, where applicable. This is consistent with the modified grounded-theory approach. We coded for the following variables as applicable and to the extent that it could be inferred from the text. Citations for each variable provide examples from the literature review in section 2 that informed this coding structure:

1) Entity: Entity, or entities, involved in drought management decision, such as tribal government, NPS, or BLM (Smit and Skinner 2002; Lesnikowski et al. 2013).

2) Drought decisions and drought decision categories: We inductively generated distinct drought decisions (e.g., sell/liquidate herd; reservoir release). Distinct management decisions were then compared, defined, expanded, and/or refined in an iterative, comparative process across and within decisions, and placed into drought decision categories (Smit et al. 2000; Biagini et al. 2014; Wilhite et al. 2000).

3) Management sector: We identified the management sector(s) addressed in the decision, which included, for example, water management, fire management, or wildlife management (Ford et al. 2015; Lesnikowski et al. 2016).

4) Spatial scale: The spatial scale of drought decisions were inductively generated, which were then grouped into four categories: 1) local-subadministrative unit, for example, allotment, field, irrigation ditch/canal; 2) administrative unit, for example, field office, reservation; 3) regional, for example, basin, statewide; and 4) national (Smit and Skinner 2002; Fidelman et al. 2013).

5) Administrative level (scale): We documented which agency/entities were involved in the decision (see 1 above) and then coded the decision for three administrative levels of decision-making: 1) individual, such as a producer; 2) intra-agency; and 3) interagency (Fidelman et al. 2013).

6) Temporal scale: Reactive decisions were defined as decisions made in response to drought during or following drought exposure or impact. Proactive decisions were defined as decisions made in preparation for drought in advance to reduce drought risk (Smit et al. 2000; Wilhite et al. 2000). Where applicable, proactive responses were further distinguished between 1) business-as-usual decisions that were 
TABLE 1. Drought decision types. For each category, the frequency of occurrence in the database (i.e., groundedness), a description of the category, number of distinct codes in the category, and example decisions (i.e., distinct codes) are included.

\begin{tabular}{|c|c|c|c|c|}
\hline Decision category & Groundedness & Description of category & $\begin{array}{c}\text { Decisions in } \\
\text { category }\end{array}$ & Example decisions \\
\hline $\begin{array}{l}\text { Operational, practice, or } \\
\text { behavior }\end{array}$ & 260 & $\begin{array}{l}\text { Changes in practices and behaviors } \\
\text { made on the ground to respond to } \\
\text { drought and reduce impacts and/or } \\
\text { to prepare for future drought }\end{array}$ & 38 & $\begin{array}{l}\text { Stocking/utilization rates; reservoir } \\
\text { release; supplement/haul water or } \\
\text { feed; prescribed fire; supplement or } \\
\text { stock fishery }\end{array}$ \\
\hline $\begin{array}{l}\text { Information and } \\
\text { technology }\end{array}$ & 111 & $\begin{array}{l}\text { Actions that help monitor baseline } \\
\text { conditions, assess state of resources, } \\
\text { forecast conditions, and/or predict } \\
\text { future change and drought impacts }\end{array}$ & 26 & $\begin{array}{l}\text { Early warning systems; NRCS drought } \\
\text { tool; risk and vulnerability } \\
\text { assessment; stream, vegetation, or } \\
\text { wildlife monitoring }\end{array}$ \\
\hline $\begin{array}{l}\text { Legal, policy, and } \\
\text { institutional } \\
\text { arrangements }\end{array}$ & 51 & $\begin{array}{l}\text { Formal and informal arrangements for } \\
\text { managing multiple uses under } \\
\text { drought; standards by which to } \\
\text { assess conditions and inform } \\
\text { decisions }\end{array}$ & 7 & $\begin{array}{l}\text { Minimum pool and in-stream flows; } \\
\text { water codes; short-term water } \\
\text { leases; rangeland and riparian } \\
\text { health standards }\end{array}$ \\
\hline $\begin{array}{l}\text { Management plans and } \\
\text { planning }\end{array}$ & 42 & $\begin{array}{l}\text { Drought-specific plans or resource- } \\
\text { specific plans with a drought com- } \\
\text { ponent; these can be preparedness } \\
\text { plans, contingency plans, or a com- } \\
\text { bination of the two }\end{array}$ & 13 & $\begin{array}{l}\text { Drought planning; grazing/allotment } \\
\text { management plans; resource } \\
\text { management plan; comprehensive } \\
\text { conservation plan; scenario } \\
\text { planning }\end{array}$ \\
\hline Physical infrastructure & 42 & $\begin{array}{l}\text { Rehabilitation of existing, or } \\
\text { construction of new, built } \\
\text { infrastructure to support drought } \\
\text { preparedness }\end{array}$ & 6 & $\begin{array}{l}\text { Fish structures-ladders and screens; } \\
\text { rehabilitate/add water develop- } \\
\text { ments for livestock; reservoir con- } \\
\text { struction and enlargement }\end{array}$ \\
\hline $\begin{array}{l}\text { Emergency, crisis } \\
\text { response }\end{array}$ & 41 & $\begin{array}{l}\text { Emergency assistance programs to } \\
\text { minimize impacts to people, } \\
\text { property, and resources }\end{array}$ & 4 & $\begin{array}{l}\text { Drought assistance programs; drought } \\
\text { declaration; drought disaster } \\
\text { declaration }\end{array}$ \\
\hline
\end{tabular}

based on historical observations of climate trends and variability or 2) anticipatory actions that considered future climate change or novel systems in planning or management activities (Boyd et al. 2015; Millar et al. 2007; Nelson et al. 2007; Tschakert and Dietrich 2010).

7) Barriers to drought management: Flagged barrier text segments were read in their entirety and distinct barriers were inductively generated. We then reviewed each barrier and the segments they were attributed to, defined them, compared them across other barriers to refine, expand, and/or merge barriers codes, and placed them into similar categories. We generally followed the typology described in Bierbaum et al. (2013), which included the following barrier types: climate change information and decision-making; lack of resources to begin and sustain adaptation efforts; fragmentation of decisionmaking; institutional constraints; lack of leadership; and divergent risk perceptions, cultures, and values. Based on our analysis, we added one category, lacking technology and infrastructure, to the typology.

Findings below are derived from primary interview data associated with the three cases from our DRAI work. As described above, we compiled each of the transcripts from the three case studies into one database and systematically coded decision types and other attributes related to the typology. Some findings from the primary interview data have been published previously. We reference those citations in the results and add those previously published insights where it supports our synthesis herein.

\section{Results}

\section{a. Drought decision-making types, management sectors, jurisdiction, and scales}

We coded 406 instances of a drought decision, or decisions, and identified 95 distinct drought management decisions, which were then summarized into six categories: physical infrastructure; emergency, crisis response; information and technology; legal, policy, and institutional arrangements; management plans and planning; and operational, practice, or behavior. Table 1 depicts the number of times each decision category was discussed in the database, a description of the category, the number of decisions that were included in the category, and examples of codes (i.e., decisions) in each category. See Figs. S1a-f in the online supplemental 
material for network views of management decision categories, inclusive codes, relationships between codes, and number of times coded in the database. Most drought decisions were changes in operations, practices, or behaviors, which typically, but not always, occurred in season. These included, for example, reservoir releases and changes to stocking and utilization rates (Table 1). This was followed by information and technologyrelated responses, and legal, policy, or institutional responses.

Table 2 illustrates the 10 most frequently referenced drought decisions. Six of the top 10 decisions were operational, practice, or behavioral decisions, while the remaining four were information and technology $(n=2)$, management planning $(n=1)$, and emergency, crisis response $(n=1)$ decisions. Five of the top 10 decisions were related to water management and two to bison and/or livestock management.

Water management actions made up most responses, which were followed by the agricultural and grazing, fish and wildlife, and rangeland management sectors (Fig. 3a). The recreation sector was the least represented sector-drought decisions in this sector were related to curtailing recreation activities (e.g., tubing, fishing). The bulk of decisions reported were made by DOI managers, followed by tribes and tribal organizations in SWSD and WRR, and private landowners and/or permittees (Fig. 3b). Within the DOI, decisions made by the BIA were the most reported, which were followed by the NPS, BLM, and FWS (Fig. 3b).

The majority of drought decisions reported across DOI, tribes, state, and private landowners were related to operational, practice, or behavioral responses (Fig. 3c). Also similar was the relative proportion of decisions described related to physical infrastructure-these made up a relatively small percentage of responses $(<10 \%)$. Further, a relatively similar proportion of emergency and crisis responses were reported among state entities, tribes, and landowners (Fig. 3c). Yet there were also differences in the types of decisions reported across jurisdictions (Figs. 3c,d). Proportionally (65\%), most permittees or private landowner decisions were operational, practice, or behavioral decisions, which included taking nonuse on grazing allotments and purchasing supplemental hay, for example. Yet private landowners also utilized information sources like the Natural Resources Conservation Service (NRCS) drought tool to inform decisions on the ground, developed drought contingency plans with the NRCS, and utilized drought assistance programs, for example (Fig. 3c). Tribes and tribal organizations reported the highest proportion of legal, policy, and institutional actions
TABLE 2. 10 most frequently referenced (i.e., highly grounded) management decisions.

\begin{tabular}{lcc}
\hline $\begin{array}{c}\text { Management decision, } \\
\text { or response }\end{array}$ & Groundedness & $\begin{array}{c}\text { Decision category } \\
\text { (from Table 1) }\end{array}$ \\
\hline $\begin{array}{l}\text { Water allocation or } \\
\text { delivery }\end{array}$ & 91 & $\begin{array}{c}\text { Operational, practice, } \\
\text { or behavior } \\
\text { Stocking/utilization rates } \\
\text { Operational, practice, } \\
\text { or behavior } \\
\text { Operational, practice, } \\
\text { or behavior }\end{array}$ \\
$\begin{array}{l}\text { Management plans and } \\
\text { planning }\end{array}$ & 49 & $\begin{array}{c}\text { Management plans } \\
\text { and planning } \\
\text { Monitoring and } \\
\text { assessment }\end{array}$ \\
$\begin{array}{l}\text { Sell or liquidate herd } \\
\text { Information and } \\
\text { technology }\end{array}$ \\
$\begin{array}{l}\text { Water rotation, ratable } \\
\text { Curtail water use }\end{array}$ & 35 & $\begin{array}{c}\text { Operational, practice, } \\
\text { or behavior } \\
\text { Operational, practice, } \\
\text { or behavior }\end{array}$ \\
$\begin{array}{l}\text { Vegetation monitoring, } \\
\text { assessment, or } \\
\text { modeling }\end{array}$ & 26 & $\begin{array}{c}\text { Operational, practice, } \\
\text { or behavior }\end{array}$ \\
$\begin{array}{l}\text { Drought declaration } \\
\text { (declaration of } \\
\text { hydrologic conditions) }\end{array}$ & 23 & $\begin{array}{c}\text { Information and } \\
\text { technology }\end{array}$ \\
\hline
\end{tabular}

$(20 \%)$. For instance, the WRR Tribal Water Code includes a process for how drought is declared and how water is allocated under a drought emergency. Tribal members we interviewed reported the lowest proportion $(32 \%)$ of operational, practice, or behavior decisions when compared with other jurisdictions (Fig. 3c). The DOI and state water managers were involved in several information and technology-related drought decisions, including monitoring and assessment of drought impacts to management sectors of concern (Fig. 3c). Across DOI bureaus, all the legal, policy, and institutional drought decisions reported were from the BIA and FWS, including, for example, contractual agreements to establish water users' associations and minimum instream flows, respectively (Fig. 3d). Management plans and planning activities were mostly reported by the NPS, while the NPS and BLM both reported relatively higher numbers of information and technology-related actions.

The proportion of reactive and proactive responses were similar ( $55 \%$ vs $45 \%$, respectively; Fig. 3e). Proactive activities included physical infrastructure improvements, such as constructing or enlarging reservoirs; gathering information and/or utilizing technologies to monitor and assess drought impacts, for example, vulnerability assessments and early warning systems; and/or drought planning efforts. Yet only a 
(a) 300

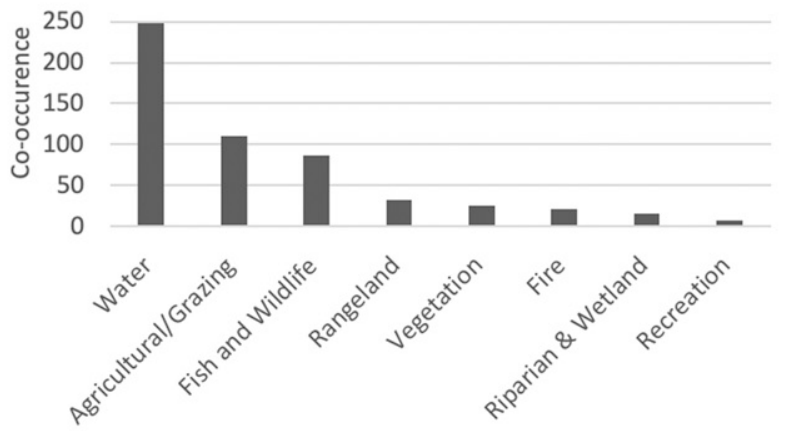

(b)

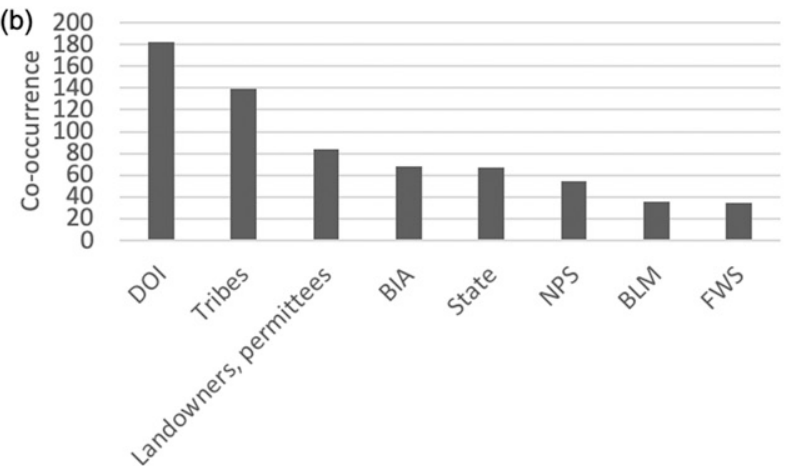

(c) $70 \%$

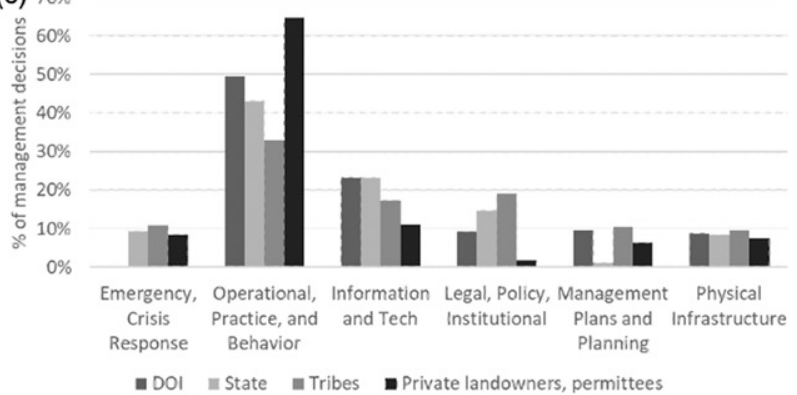

(d) $70 \%$

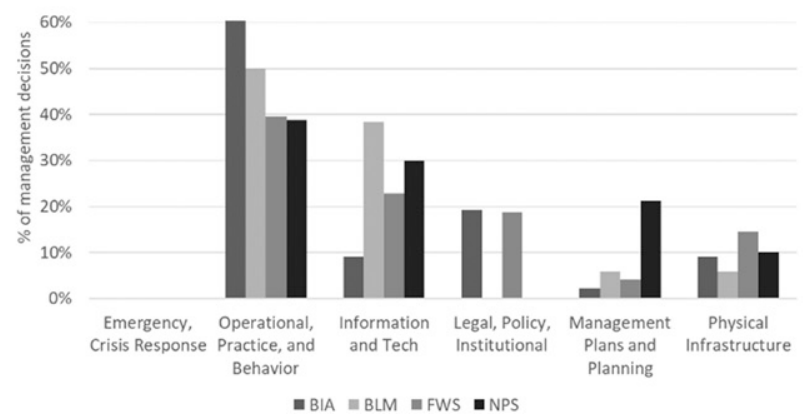

handful $(n=14)$ of proactive actions were anticipatory, that is, considered drought management in the context of projected changes in climate, or novel systems. Among DOI bureaus, anticipatory actions were exclusively (e) 250

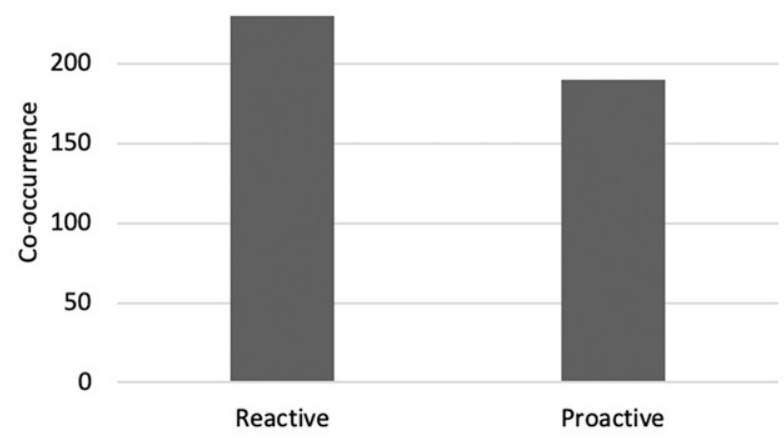

(f)

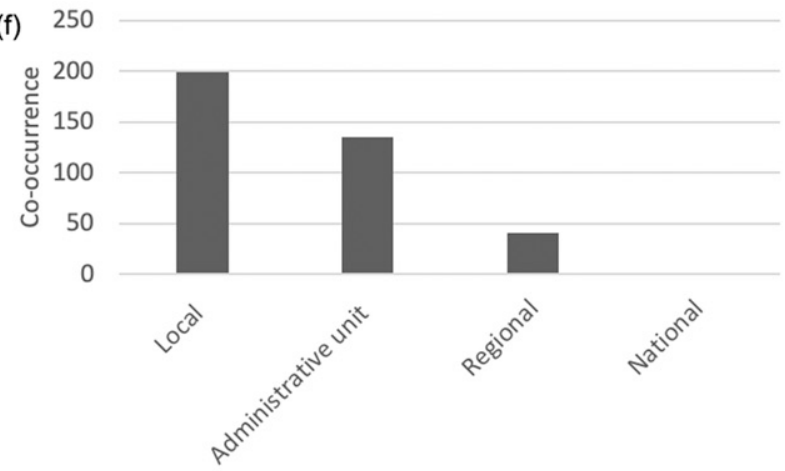

(g)

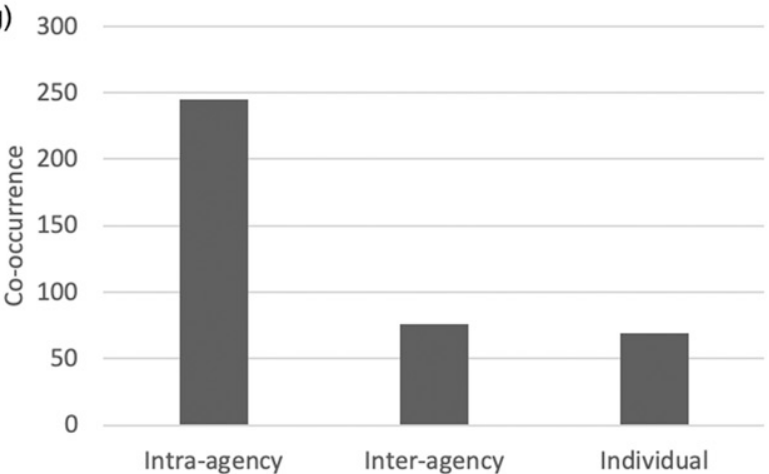

FIG. 3. Co-occurrence of management decisions with (a) sector, (b) jurisdiction, (c) decision types by jurisdiction (percent of total decision types for each jurisdiction), (d) decision types among DOI bureaus (percent of total decision types for each jurisdiction), (e) temporal scale, (f) geographic scale, and (g) administrative scale. See section 3 for acronym definitions. reported by NPS managers. These included qualitative and quantitative climate scenario planning, vulnerability assessments, and hydrologic and vegetation modeling. Also, the Upper Yampa Water Conservancy 
TABLE 3. Barrier categories including frequency of occurrence of the category in the database (i.e., groundedness), the number of codes in the category, and example codes that were inductively generated and included in the category. These categories follow Bierbaum et al. (2013) with one addition, lacking technology and infrastructure, which is indicated by italics.

\begin{tabular}{|c|c|c|c|}
\hline Barrier category & Groundedness & $\begin{array}{l}\text { Codes in } \\
\text { category }\end{array}$ & Examples \\
\hline Institutional constraints & 130 & 22 & $\begin{array}{l}\text { Bureaucracy inhibits timing of response; trust, equity, and } \\
\text { empowerment issues; lack of management authority or } \\
\text { control; limited drought assistance programs; inflexible } \\
\text { regulations, or restrictive management }\end{array}$ \\
\hline Fragmented decision-making & 54 & 8 & $\begin{array}{l}\text { Competing mandates constrain actions; fragmented and } \\
\text { fractionated ownership; limited coordination/collaboration } \\
\text { within/between agencies; management authority, or } \\
\text { responsibility, is ambiguous }\end{array}$ \\
\hline Lack of resources to sustain efforts & 51 & 3 & $\begin{array}{l}\text { Funding or financial resources; personnel (e.g., high turnover; } \\
\text { experts) }\end{array}$ \\
\hline Lacking technology and infrastructure & 49 & 6 & $\begin{array}{l}\text { Limited storage and reservoir capacity; rundown irrigation } \\
\text { system and neglected maintenance; limited on-farm tech- } \\
\text { nologies; limited measurement devices }\end{array}$ \\
\hline Climate science and information & 32 & 9 & $\begin{array}{l}\text { Lack of climate science and information considering agency } \\
\text { context; lacking local and relevant climate drivers and } \\
\text { impacts information; limited agency/organization education, } \\
\text { awareness, and understanding of drought impacts; limited } \\
\text { assessment and research on drought impacts to natural } \\
\text { resources }\end{array}$ \\
\hline $\begin{array}{l}\text { Divergent risk perceptions, cultures, } \\
\text { and values }\end{array}$ & 21 & 3 & Older generation reluctant to change; public perception differs \\
\hline Lack of leadership & 5 & 2 & $\begin{array}{l}\text { Leadership inhibits drought preparedness/response; leadership } \\
\text { lack awareness/connection to land-based livelihoods }\end{array}$ \\
\hline
\end{tabular}

District (UYWCD) commissioned a study to reconstruct the timing and severity of paleodrought to assess the potential impacts of future drought regimes on the legal and physical availability of water. ${ }^{1}$

Regarding the spatial scale of decision-making, most reported decisions occurred at the administrative unit level or lower (Fig. 3f). Relatedly, the number of intra-agency decisions far outweighed interagency decisions (Fig. 3g). A handful of regionallevel management decisions were described, which included, for example, coordinating reservoir releases and allocation at the basin level, regional monitoring networks (e.g., Greater Yellowstone Inventory and Monitoring Network), and state- or countywide drought disaster declarations. Only one drought-related management decision was reported at the national level. The InterTribal Buffalo Council was awarded a Conservation Innovation Grant from the NRCS, the purpose of which was to develop trainings to promote best management practices for drought management and guidance in the development of each member Tribe's $(n=57)$ Bison Management Plan. ${ }^{2}$

\footnotetext{
${ }^{1}$ Interviewee 1.

${ }^{2}$ Interviewee 8 .
}

\section{b. Barriers to drought decision-making}

We coded 208 instances where interviewees described a barrier, or barriers, to drought response. 53 barrier codes were inductively derived and were binned into seven different categories. These included institutional constraints; fragmented decision-making; lack of resources to sustain efforts; lacking technology and infrastructure; climate science and information; divergent risk perceptions, cultures, values; and lack of leadership (Table 3). Figures S2a-g of the online supplemental material include network views of each barrier category, inclusive codes, and code frequency. The most frequently cited barrier category was institutional constraints, which included, for example, restrictive drought management. This was followed by fragmented decisionmaking such as a lack of collaboration within or between agencies, a lack of financial and/or personnel resources to sustain efforts, and limited technology and infrastructure to support preparedness activities, such as limited stream gauges or small reservoir capacity (Table 3 ).

Six of the top 10 barriers were institutional constraints, two were related to a lack of resources to sustain efforts, and two related to fragmented decision-making (Table 4). 
TABLE 4. Top 10 reported barriers (i.e., highly grounded).

\begin{tabular}{|c|c|c|}
\hline Barriers & Groundedness & $\begin{array}{l}\text { Decision category } \\
\text { (from Table } 3 \text { ) }\end{array}$ \\
\hline BIA & 53 & Institutional constraints \\
\hline Funding or financial & 40 & $\begin{array}{l}\text { Lack of resources to } \\
\text { sustain efforts }\end{array}$ \\
\hline Personnel & 26 & $\begin{array}{l}\text { Lack of resources to } \\
\text { sustain efforts }\end{array}$ \\
\hline $\begin{array}{l}\text { Water rights and } \\
\text { allocation }\end{array}$ & 24 & Institutional constraints \\
\hline $\begin{array}{c}\text { Lack of management } \\
\text { authority/control } \\
\text { over resources }\end{array}$ & 21 & Institutional constraints \\
\hline $\begin{array}{l}\text { Rigid } \\
\text { regulations/restrictive } \\
\text { management }\end{array}$ & 18 & Institutional constraints \\
\hline $\begin{array}{l}\text { Competing uses (water } \\
\text { or land seniority; } \\
\text { preference) } \\
\text { constrains actions }\end{array}$ & 17 & Institutional constraints \\
\hline $\begin{array}{l}\text { Limited coordination } \\
\text { or collaboration } \\
\text { within/between } \\
\text { jurisdictions }\end{array}$ & 17 & $\begin{array}{l}\text { Fragmented decision- } \\
\text { making }\end{array}$ \\
\hline Mismanagement & 17 & $\begin{array}{l}\text { Fragmented decision- } \\
\text { making }\end{array}$ \\
\hline Bureaucracy & 16 & Institutional constraints \\
\hline
\end{tabular}

\section{c. Differential drought barriers and responses in the water management sector among tribes and nontribal contexts}

We describe structural barriers to drought response and preparedness and highlight how local entities are working to overcome them in tribal and nontribal water management contexts, the WRR and YRB. In the YRB, reservoir facilities are relatively small and most senior water rights are held by the agriculture and energy sectors, which creates a barrier to managing water under drought for fisheries. There is also significant water loss in the basin, which is attributed to subsurface geomorphological processes, but during drought this can limit the water that is delivered to water users, even those in priority. ${ }^{3}$ Additionally, local water managers described that rigid state regulations limited in-season flexibility to allocate water for the benefit of all users. Water users might prefer to call for stored water to satisfy a water right rather than impact the river. Yet according to state law, if there is enough water in the river to satisfy that call, calling for stored water would be considered an undecreed use. Uses that are considered undecreed are typically not protected, or escorted, downriver to water users and often restricts users from filling the following

\footnotetext{
${ }^{3}$ Interviewee 5 .
}

year. This limits flexibility for users to work together to minimize impacts to multiple uses during drought. ${ }^{4}$

Managers have taken several actions to overcome these barriers. In 2006, an enlargement of Elkhead Reservoir was completed, which provided more water closer to a critical habitat stretch for the endangered fisheries and power generation facilities with senior rights, which has helped to mitigate some of the water losses that occur (McNeeley 2014); 5000 acre feet $\left(6167400 \mathrm{~m}^{3}\right)$ were specifically designated for flow management for endangered fisheries. ${ }^{5}$ In addition, there has been an interagency effort to develop and maintain fish passages and stocking programs to keep fish alive and healthy, even in low-flow years. During the 2012 extreme drought, water managers took advantage of a 2003 state statute (HB03-1320) that allowed for short-term water leases for instream flows (McNeeley 2014). As mentioned in section 4a, the UYWCD also conducted a paleodrought study to inform future water management decisions.

At the WRR, several barriers inhibit water resources management. The tribes were awarded senior water rights in the basin following the Bighorn General Stream Adjudication, though tribal-reserved water was limited to agricultural purposes, making it difficult to manage other beneficial uses defined in their Wind River Water Code (Wind River Indian Reservation 1991). The Bighorn General Stream Adjudication also gave administrative authority of water on the WRR to the Wyoming State Water Engineer, while the BIA controls reservoir withdrawals, both of which limits tribal control and authority over water resources. The mismanagement of the reservoir by the BIA led to a water shortage in 2013, which forced producers to purchase supplemental hay, liquidate their herds, and take out loans to get by (McNeeley 2017). Although the BIA continues to collect (and increase) operation and maintenance fees in the irrigation project, much of the infrastructure is dilapidated. The U.S. Government Accountability Office (2015) estimated a deferred maintenance cost of \$30 million in fiscal year 2014 and a replacement value of $\$ 93$ million. Water managers also lacked gauges to monitor water flows and reservoir levels, which together with dilapidated infrastructure has resulted in water loss and inefficiencies (McNeeley 2017). Like the YRB, the reservoir facilities that service primarily tribal producers on the WRR are too small to capture early flows and store water until it is in demand later in the irrigation season. ${ }^{6}$

Tribal water managers were involved in several drought preparedness activities. In 2016, the WRCB

\footnotetext{
${ }^{4}$ Interviewee 1.

${ }^{5}$ https://www.coloradoriverdistrict.org/elkhead-reservoir/.

${ }^{6}$ Interviewee 40.
} 
was granted funding through the Wyoming Water Development Commission to study potential storage sites on the WRR. The study is ongoing and currently in the process of identifying one suitable site each on the Wind and Little Wind rivers for design, permitting, and construction. ${ }^{7}$ The tribes are also working to get better authority over water resources management. Water users have worked with the BIA and TWE to develop water users' associations in several BIAmanaged irrigation districts (McNeeley et al. 2018). Considered contractors to the BIA, water users associations have more control over water delivery, have developed drought contingency plans specific to the environmental and social characteristics of their respective district, and have lower operation and maintenance fees when compared to other "full service" districts. Water users associations and the TWE leveraged federal, state, and county funds to rehabilitate irrigation infrastructure, clean debris from canals, and implement invasive plant control treatments in riparian corridors, all of which help conserve water and increase efficiency (McNeeley et al. 2018). Through an informal agreement with the BIA and water users, the TWE has implemented a minimum instream flow to protect fisheries and broader riparian ecosystem health. The TWE has worked with the FWS to construct fish ladders and screens to protect culturally important fisheries (McNeeley et al. 2018), and the FWS implemented supplemental stocking programs for fisheries of tribal concern, including sauger. The tribes have also worked with multiple government and university partners to 1) conduct a community-based social-ecological vulnerability assessment to drought and 2) coproduce decision-support tools to inform drought preparedness (McNeeley et al. 2018). Finally, the TWE is using the information from the vulnerability assessment and decision-support tools to codevelop a reservation-wide drought response and preparedness plan with the study authors and the High Plains Regional Climate Center.

\section{d. Barriers to anticipatory, regional, and interagency drought response}

The lack of anticipatory, regional, and interagency actions can be explained in part by reported barriers. Anticipatory management was hampered by diverse perspectives of climate change, especially in rural communities where climate change is a politically charged issue. In the YRB, the paleodrought study discussed in section 4a did not consider future climate change

\footnotetext{
${ }^{7}$ Interviewee 40 .
}

as some members of the UYWCD did not prioritize climate change impacts assessments and felt that paleodrought studies would garner more public support than a forward-looking climate change assessment. ${ }^{8}$ Anticipatory management approaches were also limited by a lack of usable climate information. For example, the scenario assessments and planning on NPS-managed lands did not provide scientific certainty and concrete recommendations to inform decisions on the ground. ${ }^{9}$ These scenario planning exercises were later augmented with climate, vegetation, and hydrological modeling, which managers felt more confident using to inform planning and justify their management decisions. Further, limited resources (time, personnel, funding) combined with a lack of training and awareness of drought and climate change and limited agency support stymied anticipatory management. For example, a BLM manager in the YRB observed little interdepartmental and field-office-level discussions or trainings on drought or how to integrate climate-smart management actions. ${ }^{10}$ Further, while several managers wanted to incorporate anticipatory management and climate-smart practices into their management, a lack of resources and agency support limited such activities, as described by an NPS manager in SWSD:

I always think the way parks are managed and the way things get funding for often times it's not in anticipation of something it's because the fire storm is here and you get the money to do something... Right now we have our scenario planning and we talk about it and we move on to 50 other issues. ${ }^{11}$

Long-range planning efforts often fail to consider climate change impacts in drought-sensitive resources and decisions. In 2015, the BLM South Dakota Field Office completed their Resource Management Plan revision, which are the blueprints for how BLM lands are managed for the next 20-30 years. The document explicitly included climate change in their plan, though specific management actions to address climate changes were limited to reductions in greenhouse gas emissions and promoting carbon capture and storage. Drought management decisions included reactive regulatory actions, many of which were already utilized. These included, for example, stocking reductions, camping restrictions, and/or drought contingency requirements that stipulate responses according to utilization rates. ${ }^{12}$

Competing mandates, historical context and distrust between agencies, financial constraints, and a lack of

\footnotetext{
${ }^{8}$ Interviewee 1.

${ }^{9}$ Interviewee 9.

${ }^{10}$ Interviewee 3.

${ }^{11}$ Interviewee 19.

${ }^{12}$ Interviewee 10.
} 
resources hampered regional and interagency drought actions. At the WRR, differences in the BIA's Code of Federal Regulations, the state's prior appropriation system, and the Wind River Water Code created conflicts, and ambiguity in, how water was allocated during watershort years. ${ }^{13}$ The historical context and contentious relationship between the tribes and BIA at the WRR further challenged collaboration during drought, as some tribal members felt the BIA failed to honor its trust responsibility to the tribes and provide tribal resource managers with control over their own water resources:

When you have an agency like the Bureau of Indian Affairs, that has a trust responsibility to native people, they couldn't care less. They [BIA] do not pay attention to Sovereignty, Native Sovereignty. ${ }^{14}$

This was borne out during the 2013 water year when the BIA decided to release reservoir water early, despite objections from the tribes, which caused water shortages for tribal producers (McNeeley 2017). ${ }^{15}$ As a result, the TWE, Wind River Water Resources Control Board, and representatives from the BIA are rarely at the same table to discuss drought management response and preparedness strategies. Restrictions on transferring funds between agencies has also hindered collaboration between the USFS and NPS on drought and climate change-related restoration activities, such as for pest and pathogen management and prescribed fire. ${ }^{16}$ Further, the NRCS commonly works with local producers to secure funding to support improvement projects, yet some of these funding sources (e.g., Wildlife Habitat Incentive Program) are restricted to nonfederal lands. Thus, private landowners who also ranch on USFS or BLM lands may avoid coordinating improvement projects on public lands. ${ }^{17}$ Finally, while several managers supported regional, collaborative management approaches, the reality of limited time, funding, and personnel meant that the majority of resources went to taking care of day to day tasks, with limited time and resources to focus on collaborative efforts. ${ }^{18}$

\section{Discussion}

We empirically developed a typology of drought decision-making and barriers to response on public and tribal lands in high drought risk, multijurisdictional

\footnotetext{
${ }^{13}$ Interviewee 35 .

${ }^{14}$ Interviewee 23.

${ }^{15}$ Interviewees 32 and 22.

${ }^{16}$ Interviewee 9.

${ }^{17}$ Interviewee 15.

${ }^{18}$ Interviewee 4.
}

landscapes in the north-central United States. Most reported drought decisions were related to changes in 1) operations, practices, or behaviors; 2) information and technology; or 3) legal, policy, or institutional arrangements. Institutional constraints, fragmented decisionmaking, and limited financial and personnel resources were the most reported barriers. Still, there were also several differences across jurisdictions and cases. For example, as we noted in section 4c, water management challenges in the YRB were limited storage capacity, disproportionate senior water rights, water loss, and inflexible regulations, while responses to overcome these barriers included the enlargement of a reservoir to situate water closer to demand and reduce water loss, in-season water lease for instream flows, and a paleodrought study to inform future decisions. Water management challenges in the WRR included limited reservoir capacity, water rights restricted to agricultural use, limited authority to control water resources, and dilapidated and insufficient infrastructure and technology. Tribal resource managers took several preparedness actions to mitigate drought risk, for instance, development of water users associations; rehabilitation of physical infrastructure; construction of fish ladders and screens; and the coproduction of drought risk assessments, an early warning system, and a drought preparedness plan.

Managers are taking multiple proactive actions to better prepare for drought. Yet relatively few actions were anticipatory, meaning that they considered drought in the context of climate change and/or the novel systems climate change may create. This was due to several barriers, including 1) lack of usable information, particularly uncertainty in findings; 2) limited institutional support for climate change; and 3) limited resources. These findings are in line with other studies of reported barriers to climate change adaptation (e.g., Archie et al. 2014, 2012; Ellenwood et al. 2012; Kemp et al. 2015; Lemieux et al. 2013; Timberlake and Schultz 2017; Wyborn et al. 2015). Despite mandates under the Obama Administration to consider climate change in planning and management on public lands (e.g., Department of the Interior 2009; Obama 2009, 2013, 2015), implementation has not followed in lockstep. Kemp et al. (2015) found that while some federal land managers incorporated language about climate change in planning documents, no climate change adaptation or mitigation efforts were currently underway on the ground. Instead, managers used existing, incremental management strategies that were already widely supported by their agency and the public, similar to our findings from the BLM South Dakota Resource Management Plan. Similarly, a recent study found little 
to no incorporation of climate change in Colorado BLM planning documents other than cursory language (Nave et al. 2020). Responding to drought based on historical or current conditions does not necessarily make a system better adapted and may not provide the adaptive capacity needed under future drought (e.g., ChristianSmith et al. 2015; Engle 2013). Responding to future drought will likely require a mix of existing incremental approaches and more anticipatory, perhaps even transformational, actions (Kates et al. 2012; McWethy et al. 2019; Nelson et al. 2007).

Interagency partnerships and collaboration are necessary to bridge financial and institutional barriers and build capacity to better respond to drought. Yet most reported decisions were made within agencies and at the administrative unit level or lower. A lack of collaboration across entities and landscapes was due to competing mandates, financial issues transferring funds across agencies, historical context and trust issues, and limited time, financial, and/or personnel resources. As drought crosses administrative and geographic boundaries, a mismatch in the scale of drought exposure and the scale of response can occur (Cash et al. 2006; Crowder et al. 2006; Cumming et al. 2015). Thus, there is a need for 1) increased investment in financing mechanisms supporting regional and interagency partnerships, 2) requirements for cross-jurisdictional collaboration, and 3 ) coordinated interagency federal priorities on drought management (Brugger et al. 2018; Mount et al. 2016). It will require streamlining financial transfers between agencies and investments to support conflict resolution and build relationships. Several programs were developed to overcome these issues, such as the Landscape Conservation Cooperatives, Joint Chiefs' Landscape Restoration Partnership, and the Collaborative Forest Landscape Restoration Program. Our findings suggest one additional point-cross-boundary and interagency initiatives may be more likely embraced with more internal, intra-agency support. In other words, internal funding and other related resources, such as hiring and keeping key personnel, are necessary to support managers in conducting and completing day-to-day activities, which may, in turn, help managers feel more confident in spending time and resources to cooperate in cross-jurisdictional and regional landscape management planning and restoration.

Several limitations need to be acknowledged. First, these findings represent a subset of the types of decisions and barriers to decision-making managers we interviewed experienced. They should not be interpreted as representative of all the decisions or barriers managers experienced in the context of drought. Second, and relatedly, while findings indicate common themes in drought response and preparedness among tribal and public land managers in the north-central United States, statistical relationships inferring difference or similarities among groups and contexts was not possible due to our sample size and approach. Third, we relied on local observations among managers to report on the drought decisions they made. Thus, one could argue that the decisions described and the lack of interagency, anticipatory, and regional to national-level actions could be an artifact of our sample and not reflective of broader trends. We took several measures to ensure that this bias was limited-our interview protocol asked specific questions about the management decisions managers make in the context of drought, who they collaborate with in drought management and what conflicts arise among entities, and whether they have the capacity to prepare for and respond to drought.

\section{Conclusions}

We developed a drought management decision typology of the who, what, where, when, and how of decision-making on public and tribal lands in three multijurisdictional landscapes across the north-central United States. We relied on in-depth, semistructured interviews with land and resource managers from the Department of the Interior, tribes and tribal organizations, the Natural Resources Conservation Service, and state agencies. Findings indicated key similarities and differences in drought decisions and barriers to decision-making across jurisdictions, cases, and management sectors.

Two key commonalities in drought response and the barriers to response are important to consider here. First, managers engaged in several proactive actions to reduce drought risk. Yet only a handful in this study explicitly considered future drought regimes in the context of climate change. Thus, strategic planning that considers the impacts of future droughts on management issues of concern and evaluates whether current management decisions are appropriate under projected changes, or whether they need to be reconsidered, is warranted. Second, relatively few cross-boundary and regional- to national-level drought responses were reported. These decisions were constrained by competing mandates, resource constraints, and distrust. Intra-agency support to carry out day-to-day tasks, financial mechanisms to support interagency work, requirements for collaboration, and coordination of drought priorities across agencies can help overcome these barriers. Considering future drought impacts on management issues of concern and more strategic engagement with cross-boundary collaboration and management will enhance resilience to climate change and match the 
scale of drought exposure with the scale of drought response (Engle 2013; Crowder et al. 2006). This study underscores the importance of conducting comparative cases studies, which can help document contextspecific factors that determine drought vulnerability and adaptation, as well as broader generalizations and management gaps across cases and management contexts (Ford et al. 2010; McNeeley et al. 2017a). All of this contributes to the goal of developing drought science that is actionable for decision-making.

Acknowledgments. We thank three anonymous reviewers for their valuable input. We thank the managers that shared their local knowledges and observations. We acknowledge Amanda Cravens, Nina Burkardt, Adam Wilke, Dennis Ojima, Jack Friedman, Jamie McEvoy, and other members of the Social Science Drought Synthesis Working Group. The authors participated in this working group along with several other regional experts on drought social science, which involved multiple synthesis webinars and an in-person meeting 5-7 June 2018, at the Powell Center of the USGS Fort Collins Science Center. Some of the concepts and ideas presented in this paper were derived from these discussions and meetings. We also thank Robert Flynn for his help in creating Fig. 1. The project described in this publication was supported by funding from the U.S. Department of the Interior North Central Climate Adaptation Science Center, which is managed by the U.S. Geological Survey National Climate Adaptation Science Center (G17AC00284; G14AP00180). Its contents are solely the responsibility of the authors and do not necessarily represent the views of the North Central Climate Adaptation Science Center, the National Climate Adaptation Science Center, or the U.S. Geological Survey. This paper is submitted for publication with the understanding that the U.S. government is authorized to reproduce and distribute reprints for governmental purposes. Any use of trade, product, or firm names is for descriptive purposes only and does not imply endorsement by the U.S. government. The authors declare no conflicts of interest.

\section{APPENDIX}

\section{Interview Questions Protocol}

The following list gives the protocol for the interview questions used in this study.

1) How do you define or think about drought in the context of your landscape?

2) Do you view drought as a significant risk to your management activities?
3) [if yes to \#2] At what time of year is drought most problematic (how/why)?

4) What year (or years) was the worst drought in this area? What happened?

5) What management decisions do you have to make that are affected by drought?

6) (i) What, if any, indicators do you use to know if/when/how drought is going to cause negative impacts on your landscape? (ii) What do you consider to be the best source or sources of information on drought?

7) Are there fish, wildlife, and/or plant species you haven't mentioned impacted by drought in your landscape?

8) (i) Are there human livelihoods or other activities impacted by drought in your landscape? (ii) Does this cause any conflicts? (iii) Do you collaborate with other stakeholders or jurisdictions on droughtrelated issues? If so, with whom and how?

9) Do you have the capacity to either respond to or prepare for drought?

10) Are there barriers that inhibit your ability to respond to or prepare for drought?

11) Is there anything else that we have not discussed?

\section{REFERENCES}

Adger, W. N., and Coauthors, 2007: Assessment of adaptation practices, options, constraints and capacity. Climate Change 2007: Impacts, Adaptation and Vulnerability, M. L. Parry et al., Eds., Cambridge University Press, 717-743.

AghaKouchak, A., D. Feldman, M. Hoerling, T. Huxman, and J. Lund, 2015: Water and climate: Recognize anthropogenic drought. Nature, 524, 409-411, https://doi.org/10.1038/ 524409a.

Archie, K. M., L. Dilling, J. B. Milford, and F. C. Pampel, 2012: Climate change and western public lands: A survey of U.S. federal land managers on the status of adaptation efforts. Ecol. Soc., 17, 20, https://doi.org/10.5751/ES-05187-170420.

$-, \ldots,-$, and,- 2014 : Unpacking the 'information barrier': Comparing perspectives on information as a barrier to climate change adaptation in the interior mountain west. J. Environ. Manage., 133, 397-410, https://doi.org/10.1016/ j.jenvman.2013.12.015.

Beeton, T. A., and S. M. McNeeley, 2020: San Luis Valley Field Office social vulnerability assessment to climate variability and change. Colorado State University Natural Resource Ecology Laboratory Rep., 66 pp., https://cnhp.colostate.edu/ wp-content/uploads/download/documents/misc/COBLM-SLVSVA_Technical-Assessment_Report-Final.pdf.

,-- , B. W. Miller, and D. S. Ojima, 2019: Grounding simulation models with qualitative case studies: Toward a holistic framework to make climate science usable for US public land management. Climate Risk Manage., 23, 50-66, https://doi.org/ 10.1016/j.crm.2018.09.002.

Bernard, H. R., 2011: Research Methods in Anthropology: Qualitative and Quantitative Approaches. AltaMira Press, 680 pp. 
Biagini, B., R. Bierbaum, M. Stults, S. Dobardzic, and S. M. McNeeley, 2014: A typology of adaptation actions: A global look at climate adaptation actions financed through the global environment facility. Global Environ. Change, 25, 97-108, https://doi.org/10.1016/j.gloenvcha.2014.01.003.

Bierbaum, R., and Coauthors, 2013: A comprehensive review of climate adaptation in the United States: More than before, but less than needed. Mitigation Adapt. Strategies Global Change, 18, 361-406, https://doi.org/10.1007/s11027-012-9423-1.

Biesbroek, G. R., J. E. M. Klostermann, C. J. A. M. Termeer, and P. Kabat, 2013: On the nature of barriers to climate change adaptation. Reg. Environ. Change, 13, 1119-1129, https:// doi.org/10.1007/s10113-013-0421-y.

Boyd, E., B. Nykvist, S. Borgström, and I. A. Stacewicz, 2015: Anticipatory governance for social-ecological resilience. AMBIO, 44, 149-161, https://doi.org/10.1007/s13280-0140604-x.

Brugger, J., K. L. Hawkes, A. M. Bowen, and M. P. McClaran, 2018: Framework for a collaborative process to increase preparation for drought on U.S. public rangelands. Ecol. Soc., 23, 18, https://doi.org/10.5751/ES-10503-230418.

Bryant, A., and K. Charmaz, 2007: The SAGE Handbook of Grounded Theory. SAGE Publications, $656 \mathrm{pp}$.

Cai, X., R. Zeng, W. H. Kang, J. Song, and A. J. Valocchi, 2015: Strategic planning for drought mitigation under climate change. J. Water Resour. Plann. Manage., 141, 04015004, https://doi.org/10.1061/(ASCE)WR.1943-5452.0000510.

Cash, D. W., W. N. Adger, F. Berkes, P. Garden, L. Lebel, P. Olsson, L. Pritchard, and O. Young, 2006: Scale and cross-scale dynamics: Governance and information in a multilevel world. Ecol. Soc., 11, 8, https://doi.org/10.5751/ES-01759-110208.

Charmaz, K., 2006: Constructing Grounded Theory: A Practical Guide Through Qualitative Research. Sage Publications, 224 pp.

, 2011: A constructivist grounded theory analysis of losing and regaining a valued self. Five Ways of Doing Qualitative Analysis: Phenomenological Psychology, Grounded Theory, Discourse Analysis, Narrative Research, and Intuitive Inquiry, F. J. Wertz et al., Eds., Guilford Press, 165-204.

Chief, K., A. Meadow, and K. Whyte, 2016: Engaging Southwestern tribes in sustainable water resources topics and management. Water, 8, 350, https://doi.org/10.3390/w8080350.

Christian-Smith, J., M. C. Levy, and P. H. Gleick, 2015: Maladaptation to drought: A case report from California, USA. Sustainability Sci., 10, 491-501, https://doi.org/10.1007/ s11625-014-0269-1.

Conant, R. T., and Coauthors, 2018: Northern Great Plains. Impacts, Risks, and Adaptation in the United States, D. R. Reidmiller et al., Eds., Vol. II, The Fourth National Climate Assessment, U.S. Global Change Research Program, 941-986, https://doi.org/10.7930/NCA4.2018.CH22.

Cook, B. I., T. R. Ault, and J. E. Smerdon, 2015: Unprecedented 21st century drought risk in the American southwest and central plains. Sci. Adv., 1, e1400082, https://doi.org/10.1126/ sciadv.1400082.

Corbin, J., and A. Strauss, 2008: Basics of Qualitative Research: Techniques and Procedures for Developing Grounded Theory. Sage Publications, 400 pp.

Crowder, L. B., and Coauthors, 2006: Resolving mismatches in US ocean governance. Science, 313, 617-618, https://doi.org/ 10.1126/science.1129706.

Cumming, C. R., and Coauthors, 2015: Understanding protected area resilience: A multi-scale, social-ecological approach. Ecol. Appl., 25, 299-319, https://doi.org/10.1890/13-2113.1.
Department of the Interior, 2009: Addressing the impacts of climate change on America's water, land, and other natural and cultural resources. DOI Order 3289, Code of Federal Regulations 3, 4 pp., https://www.fws.gov/home/climatechange/ pdf/SecOrder3289.pdf.

Dilling, L., M. E. Daly, D. A. Kenney, R. Klein, K. Miller, A. J. Ray, W. R. Travis, and O. Wilhelmi, 2019: Drought in urban water systems: Learning lessons for climate adaptive capacity. Climate Risk Manage., 23, 32-42, https://doi.org/ 10.1016/j.crm.2018.11.001

Eisenack, K., S. C. Moser, E. Hoffmann, R. J. T. Klein, C. Oberlack, A. Pechan, M. Rotter, and C. J. A. M. Termeer, 2014: Explaining and overcoming barriers to climate change adaptation. Nat. Climate Change, 4, 867-872, https://doi.org/ 10.1038/nclimate2350.

Ellenwood, M. S., L. Dilling, and J. B. Milford, 2012: Managing United States public lands in response to climate change: A view from the ground up. Environ. Manage., 49, 954-967, https://doi.org/10.1007/s00267-012-9829-2.

Engle, N. L., 2012: Adaptation bridges and barriers in water planning and management: Insight from recent extreme droughts in Arizona and Georgia. J. Amer. Water Resour. Assoc., 48, 11391150, https://doi.org/10.1111/j.1752-1688.2012.00676.x.

- 2013: The role of drought preparedness in building and mobilizing adaptive capacity in states and their community water systems. Climatic Change, 118, 291-306, https://doi.org/ 10.1007/s10584-012-0657-4.

Fidelman, P. I. J., A. M. Leitch, and D. R. Nelson, 2013: Unpacking multilevel adaptation to climate change in the Great Barrier Reef, Australia. Global Environ. Change, 23, 800-812, https:// doi.org/10.1016/j.gloenvcha.2013.02.016.

Ford, J. D., E. C. H. Keskitalo, T. Smith, T. Pearce, L. BerrangFord, F. Duerden, and B. Smit, 2010: Case study and analogue methodologies in climate change vulnerability research. Wiley Interdiscip. Rev.: Climate Change, 1, 374-392, https://doi.org/ 10.1002/WCC.48.

, L. Berrang-Ford, A. Bunce, C. McKay, M. Irwin, and T. Pearce, 2015: The status of climate change adaptation in Africa and Asia. Reg. Environ. Change, 15, 801-814, https:// doi.org/10.1007/s10113-014-0648-2.

Fu, X., M. Svoboda, Z. Tang, Z. Dai, and J. Wu, 2013: An overview of US state drought plans: Crisis or risk management? Nat. Hazards, 69, 1607-1627, https://doi.org/10.1007/s11069-013-0766-z.

Füssel, H.-M., and R. J. T. Klein, 2006: Climate change vulnerability assessments: An evolution of conceptual thinking. Climatic Change, 75, 301-329, https://doi.org/10.1007/s10584-006-0329-3.

Glantz, M. H., 1994: Drought Follows the Plow: Cultivating Marginal Areas. Cambridge University Press, 197 pp.

Glaser, B., and A. Strauss, 1967: The Discovery of Grounded Theory: Strategies for Qualitative Research. Aldine, 271 pp.

Gonzalez, P., and Coauthors, 2018: Southwest. Impacts, Risks, and Adaptation in the United States, D. R. Reidmiller et al., Eds., Vol. II, The Fourth National Climate Assessment, U.S. Global Change Research Program, 1101-1184, https:// doi.org/10.7930/NCA4.2018.CH25.

Haigh, T. R., W. Schacht, C. L. Knutson, A. J. Smart, J. Volesky, C. Allen, M. Hayes, and M. Burbach, 2019: Socioecological determinants of drought impacts and coping strategies for ranching operations in the Great Plains. Rangeland Ecol. Manage., 72, 561-571, https://doi.org/10.1016/j.rama.2019.01.002.

Hayes, M. J., O. V. Wilhelmi, and C. L. Knutson, 2004: Reducing drought risk: Bridging theory and practice. Nat. Hazards Rev., 5, 106-113, https://doi.org/10.1061/(ASCE)1527-6988(2004)5:2(106). 
Hill, M., and N. L. Engle, 2013: Adaptive capacity: Tensions across scales. Environ. Policy Governance, 23, 177-192, https:// doi.org/10.1002/eet.1610.

Jantarasami, L. C., J. J. Lawler, and C. W. Thomas, 2010: Institutional barriers to climate change adaptation in US national parks and forests. Ecol. Soc., 15, 33, https://doi.org/ 10.5751/ES-03715-150433.

Jedd, T. M., 2019: The limits of resilience in US community responses to recent drought events. Community Dev., 50, 141159, https://doi.org/10.1080/15575330.2019.1574850.

— - and Coauthors, 2018: Tracking drought perspectives: A rural case study of transformations following an invisible hazard. Wea. Climate Soc., 10, 653-672, https://doi.org/ 10.1175/WCAS-D-17-0067.1.

Kachergis, E., J. D. Derner, B. B. Cutts, L. M. Roche, V. T. Eviner, M. N. Lubell, and K. W. Tate, 2014: Increasing flexibility in rangeland management during drought. Ecosphere, 5, 77, https://doi.org/10.1890/ES13-00402.1.

Kallis, G., 2008: Droughts. Annu. Rev. Environ. Resour., 33, 85-118, https://doi.org/10.1146/annurev.environ.33.081307.123117.

Kates, R. W., W. R. Travis, and T. J. Wilbanks, 2012: Transformational adaptation when incremental adaptations to climate change are insufficient. Proc. Natl. Acad. Sci. USA, 109, 7156-7161, https:// doi.org/10.1073/pnas.1115521109.

Kemp, K. B., J. J. Blades, P. Z. Klos, T. E. Hall, J. E. Force, P. Morgan, and W. T. Tinkham, 2015: Managing for climate change on federal lands of the western United States: Perceived usefulness of climate science, effectiveness of adaptation strategies, and barriers to implementation. Ecol. Soc., 20, 17, https://doi.org/10.5751/ES-07522-200217.

Lemieux, C. J., J. L. Thompson, J. Dawson, and R. M. Schuster, 2013: Natural resource manager perceptions of agency performance on climate change. J. Environ. Manage., 114, 178189, https://doi.org/10.1016/j.jenvman.2012.09.014.

Lesnikowski, A. C., J. D. Ford, L. Berrang-Ford, M. Barrera, and J. Heymann, 2013: How are we adapting to climate change? A global assessment. Mitigation Adapt. Strategies Global Change, 20, 277-293, https://doi.org/10.1007/s11027-013-9491-x.

,,-- R. Biesbroek, L. Berrang-Ford, and S. J. Heymann, 2016: National-level progress on adaptation. Nat. Climate Change, 6, 261-264, https://doi.org/10.1038/nclimate2863.

McNeeley, S. M., 2014: A “toad's eye" view of drought: Regional socio-natural vulnerability and responses in 2002 in northwest Colorado. Reg. Environ. Change, 14, 1451-1461, https:// doi.org/10.1007/s10113-014-0585-0.

_ 2017: Sustainable climate change adaptation in Indian country. Wea. Climate Soc., 9, 393-404, https://doi.org/10.1175/ WCAS-D-16-0121.1.

—, and M. D. Shulski, 2011: Anatomy of a closing window: Vulnerability to changing seasonality in Interior Alaska. Global Environ. Change, 21, 464-473, https://doi.org/10.1016/ j.gloenvcha.2011.02.003.

— T. T. A. Beeton, and D. S. Ojima, 2016: Drought risk and adaptation in the interior United States: Understanding the importance of local context for resource management in times of drought. Wea. Climate Soc., 8, 147-161, https://doi.org/ 10.1175/WCAS-D-15-0042.1.

, T. L. Even, J. B. Gioia, C. N. Knapp, and T. A. Beeton, 2017a: Expanding vulnerability assessment for public lands: The social complement to ecological approaches. Climate Risk Manage., 16, 106-119, https://doi.org/10.1016/j.crm.2017.01.005.

C. N. Knapp, T. L. Even, J. Goia, and J. Nave, 2017b: Colorado Bureau of Land Management: social vulnerability assessment. Colorado State University Natural Resource Ecology Laboratory Rep., 209 pp., https://cnhp.colostate.edu/ wp-content/uploads/download/documents/misc/COBLM_SocialVulnerability-Assessment_Final-Report_7-26-19.pdf.

, C. F. Dewes, C. J. Stiles, T. A. Beeton, I. Rangwala, M. T. Hobbins, and C. L. Knutson, 2018: Anatomy of an interrupted irrigation season: Micro-drought at the Wind River Indian Reservation. Climate Risk Manage., 19, 61-82, https://doi.org/ 10.1016/j.crm.2017.09.004.

McWethy, D. B., and Coauthors, 2019: Rethinking resilience to wildfire. Nat. Sustainability, 2, 797-804, https://doi.org/ 10.1038/s41893-019-0353-8.

Meempatta, L., A. J. Webb, A. C. Horne, L. A. Keogh, A. Loch, and M. J. Stewardson, 2019: Reviewing the decision-making behavior of irrigators. Wiley Interdiscip. Rev.: Water, 6, e1366, https://doi.org/10.1002/wat2.1366.

Millar, C. I., N. L. Stephenson, and S. L. Stephens, 2007: Climate change and forests of the future: Managing in the face of uncertainty. Ecol. Appl., 17, 2145-2151, https://doi.org/10.1890/ 06-1715.1.

Mills, J., A. Bonner, and K. Francis, 2006: The development of constructivist grounded theory. Int. J. Qual. Methods, 5, 25-35, https://doi.org/10.1177/160940690600500103.

Moser, S. C., and J. A. Ekstrom, 2010: A framework to diagnose barriers to climate change adaptation. Proc. Natl. Acad. Sci. USA, 107, 22 026-22 031, https://doi.org/10.1073/ pnas.1007887107.

Mount, J., and Coauthors, 2016: Improving the federal response to western drought. Calif. J. Politics Policy, 8, https://doi.org/ 10.5070/P2CJPP8331897.

Nave, J. C. C., C. N. Knapp, and S. M. McNeeley, 2020: Planning for change?: Assessing the integration of climate change and land-based livelihoods in Colorado BLM planning documents. Reg. Environ. Change, 20, 29, https://doi.org/10.1007/s10113020-01590-0.

Nelson, D. R., W. N. Adger, and K. Brown, 2007: Adaptation to environmental change: Contributions of a resilience framework. Annu. Rev. Environ. Resour., 32, 395-419, https:// doi.org/10.1146/annurev.energy.32.051807.090348.

Obama, B., 2009: Federal leadership in environmental, energy, and economic performance. Executive Order 13514, Code of Federal Regulations 3, 13 pp., https://www.govinfo.gov/ content/pkg/DCPD-200900783/pdf/DCPD-200900783.pdf.

- 2013: Preparing the United States for the impacts of climate change. Executive Order 13653, Code of Federal Regulations 3, 7 pp., https://www.govinfo.gov/content/pkg/CFR-2014title3-vol1/pdf/CFR-2014-title3-vol1-eo13653.pdf.

_ 2015: Planning for federal sustainability in the next decade. Executive Order 13693, Code of Federal Regulations 3, 16 pp., https://www.govinfo.gov/content/pkg/CFR-2016-title3-vol1/ pdf/CFR-2016-title3-vol1-eo13693.pdf.

O'Brien, K., S. Eriksen, L. P. Nygaard, and A. Schjolden, 2007: Why different interpretations of vulnerability matter in climate change discourses. Climate Policy, 7, 73-88, https:// doi.org/10.1080/14693062.2007.9685639.

Patton, M. Q., 2002: Qualitative Research and Evaluation Methods. Sage Publications, $598 \mathrm{pp}$.

Renn, O., 2011: The social amplification/attenuation of risk framework: Application to climate change. Wiley Interdiscip. Rev.: Climate Change, 2, 154-169, https://doi.org/10.1002/WCC.99.

Risbey, J., M. Kandlikar, H. Dowlatabadi, and D. Graetz, 1999: Scale, context, and decision making in agricultural adaptation to climate variability and change. Mitigation Adapt. 
Strategies Global Change, 4, 137-165, https://doi.org/10.1023/ A:1009636607038.

Robinson, S., 2017: Climate change adaptation trends in small island developing states. Mitigation Adapt. Strategies Global Change, 22, 669-691, https://doi.org/10.1007/s11027-015-9693-5.

Smit, B., and M. W. Skinner, 2002: Adaptation options in agriculture to climate change: A typology. Mitigation Adapt. Strategies Global Change, 7, 85-114, https://doi.org/10.1023/ A:1015862228270.

- , and O. Pilifosova, 2003: Adaptation to climate change in the context of sustainable development and equity. Climate Change 2001: Impacts, Adaptation, and Vulnerability, J. J. McCarthy et al., Eds., Cambridge University Press, 877-912.

_ vulnerability. Global Environ. Change, 16, 282-292, https:// doi.org/10.1016/j.gloenvcha.2006.03.008.

_- I. Burton, R. J. Klein, and J. Wandel, 2000: An anatomy of adaptation to climate change and variability. Climatic Change, 45, 223-251, https://doi.org/10.1023/A:1005661622966.

Thornberg, R., 2012: Informed grounded theory. Scand. J. Educ. Res., 56, 243-259, https://doi.org/10.1080/00313831.2011.581686.

Timberlake, T. J., and C. A. Schultz, 2017: Policy, practice, and partnerships for climate change adaptation on US national forests. Climatic Change, 144, 257-269, https://doi.org/10.1007/ s10584-017-2031-z.

Travis, W. R., 2010: Going to extremes: Propositions on the social response to severe climate change. Climatic Change, 98, 1-19, https://doi.org/10.1007/s10584-009-9661-8.

Tschakert, P., and K. A. Dietrich, 2010: Anticipatory learning for climate change adaptation and resilience. Ecol. Soc., 15, 11, https://doi.org/10.5751/ES-03335-150211.

U.S. Government Accountability Office, 2015: Indian irrigation projects: Deferred maintenance and financial sustainability issues remain unresolved. U.S. GAO Doc., 19 pp., http:// www.gao.gov/assets/670/668857.pdf.
Van Loon, A. F., and Coauthors, 2016: Drought in the Anthropocene. Nat. Geosci., 9, 89-91, https://doi.org/ 10.1038/ngeo2646.

Wandel, J., H. Diaz, J. Warren, M. Hadarits, M. Hurlbert, and J. Pittman, 2016: Drought and vulnerability: A conceptual approach. Vulnerability and Adaptation to Drought: The Canadian Prairies and South America, H. Diaz, M. Hurlbert, and J. Warren, Eds., Energy, Ecology, and the Environment Series, University of Calgary Press, 15-36.

Wilhite, D. A., 2000: Drought as a natural hazard: Concepts and definitions. Drought: A Global Assessment, D. A. Wilhite, Ed., Routledge Studies in Hazards, Disaster Risk and Climate Change, Vol. I, Routledge, 3-18.

_ 2017: Drought management and policy: Changing the paradigm from crisis to risk management. European Water, 16, 181-187.

—, M. J. Hayes, C. Knutson, and K. H. Smith, 2000: Planning for drought: Moving from crisis to risk management. J. Amer. Water Resour. Assoc., 36, 697-710, https://doi.org/10.1111/ j.1752-1688.2000.tb04299.x.

_ M. V. K. Sivakumar, and R. Pulwarty, 2014: Managing drought risk in a changing climate: The role of national drought policy. Wea. Climate Extremes, 3, 4-13, https:// doi.org/10.1016/j.wace.2014.01.002.

Wilmer, H., and M. E. Fernández-Giménez, 2015: Rethinking rancher decision-making: A grounded theory of ranching approaches to drought and succession management. Rangeland J., 37, 517, https://doi.org/10.1071/RJ15017.

Wind River Indian Reservation, 1991: Wind River Water Code. $22 \mathrm{pp}$.

Wyborn, C., L. Yung, D. Murphy, and D. R. Williams, 2015: Situating adaptation: How governance challenges and perceptions of uncertainty influence adaptation in the Rocky Mountains. Reg. Environ. Change, 15, 669-682, https://doi.org/ 10.1007/s10113-014-0663-3. 